\title{
Fish Karyome: A karyological information network database of Indian Fishes
}

\author{
Naresh Sahebrao Nagpure, Ajey Kumar Pathak*, Rameshwar Pati, Shri Prakash Singh, \\ Mahender Singh, Uttam Kumar Sarkar, Basdeo Kushwaha \& Ravindra Kumar
}

National Bureau of Fish Genetic Resources, Canal Ring Road, Post - Dilkusha, Telibagh, Lucknow- 226002, U P India; Ajey Kumar Pathak - Email: pathakajey@rediffmail.com; Phone: +91-522-2442440; Fax: +91-522-2442403; *Corresponding author

Received April 17, 2012; Accepted April 27, 2012; Published May 15, 2012

\begin{abstract}
'Fish Karyome', a database on karyological information of Indian fishes have been developed that serves as central source for karyotype data about Indian fishes compiled from the published literature. Fish Karyome has been intended to serve as a liaison tool for the researchers and contains karyological information about 171 out of 2438 finfish species reported in India and is publically available via World Wide Web. The database provides information on chromosome number, morphology, sex chromosomes, karyotype formula and cytogenetic markers etc. Additionally, it also provides the phenotypic information that includes species name, its classification, and locality of sample collection, common name, local name, sex, geographical distribution, and IUCN Red list status. Besides, fish and karyotype images, references for 171 finfish species have been included in the database. Fish Karyome has been developed using SQL Server 2008, a relational database management system, Microsoft's ASP.NET-2008 and Macromedia's FLASH Technology under Windows 7 operating environment. The system also enables users to input new information and images into the database, search and view the information and images of interest using various search options. Fish Karyome has wide range of applications in species characterization and identification, sex determination, chromosomal mapping, karyo-evolution and systematics of fishes.
\end{abstract}

Availability: http://www.nbfgr.res.in/fishkaryome/

Key words: Karyological Information Network, Chromosome, Finfish Species, Internet-Database System, Karyotype

\section{Background:}

Fishes are the most diverse group of vertebrates, with ca. 32200 species (http://www.fishbase.org) characterized by great diversity of their morphology, physiology, ecology, life history and behaviour. The classical methodology for identification of fish species is based on morphometric and meristic characteristics that cannot precisely identify and characterize closely related fish species and subspecies leading to problems of fisheries management [1]. Cytogenetic markers are authentic tools for characterization of fish species as well as to screen putative hybrids $[\mathbf{1}, \mathbf{2}]$. These markers were found useful for detection of intraspecific stocks and populations within species
[3] and in resolving taxonomic ambiguities between some species [4]. Cytogenetic investigations, thus have gained importance in species characterization, evolution and systematics, mutagenesis, environmental toxicology, aquaculture [4-7] and eventually for conservation and sustainable utilization of aquatic biodiversity. India is rich in fish diversity, which is reflected in its large number of documented 2438 finfish species [8] which includes 1370 (63\%) species from marine ecosystem; however the basic karyomorphological data is available for about 200 species [9-13]. Further, marine fishes have not received much deserved attention towards their genetic characterization since a little 
over 45 marine species have been cytogenetically characterized $[10,13,14]$. Attempts were made worldwide for documenting cytogenetic information in the form of digital databases such as Atlas of Genetics and Cytogenetics in Oncology and Haematology (http://atlasgeneticsoncology.org/), Cytogenetics and Chromosome disorders (http://www.vivo.colostate. edu/hbooks/genetics /medgen/chromo/index.html), Cytogenetics Gallery(http://www.pathology.washington.edu/galleries/cytogallery /main.php), General Cytogenetics Information, Cytogenetics Resources (http://www .kumc.edu /gec/prof/ cytogene.html), Human Cytogenetic Database (http:// www. ncbi.nlm. nih.gov/ pmc/ articles/ PMC1016683/), Online Cytogenetics of Animals (OCOA) (http://www.angis.org.au/ Databases/Birx/ocoa/) etc. As digital databases are not available on fish chromosomes in public domain, we developed an Internet-database named 'Fish Karyome' with a view to systematically maintain the karyotype information from various published sources about Indian fish species from different eco regions. In addition to the karyological information, we also collected the phenotypic information of the fishes. At present, Fish Karyome contains karyotype information about 171 finfish species. The database has been opened to the public on web page that provides information on chromosome number and morphology, sex chromosomes, karyotype formula and cytogenetic markers like nucleolar organiser regions, constitutive heterochromatic bands etc. Additionally, it provides images of karyotype, fish images, taxonomy, locality, geographical distribution, IUCN Red list status and references.

\section{Methodology:}

\section{Data overview}

To develop the Fish Karyome database a majority of the information was taken from 'Fish Chromosome Atlas of India' [13] and 'Fish Chromosome Search Software' [15]. Additionally, we collected karyotype and the phenotypic information including the photograph of fishes from different published sources. Table 1 (see supplementary material) shows the list of parameters selected to collect the karyotype and phenotypic information about the fish species. At present, we have documented 377 karyological and phenotypic records of 171 Indian fish species from 43 families and 10 orders.

\section{Development of the Internet-database Database structure and development}

We used SQL Server 2008, a relational database management systems to build the database. The database contains interrelated eight tables to store the relevant information about 171 fish species of India. Table 2 (see supplementary material) shows the table names with description and (Figure 2) shows the structure of the database.

\section{Web interface}

The web interface for the database was developed using ASP.NET's Integrated Development Environment. We incorporated user friendly tools in the interface integrated with database to provide convenience to work with the database. The web interface utilizes HTML (Hyper Text Markup Language), CSS (Cascading Style Sheets) and ASP Scripts (Active Server pages) to provide the static and dynamic content to the user. We included all the database management functions in the web interface for security reasons. The web interface along with database was implemented on Windows Sever running Internet Information Server. (Figure 1) shows the architecture of the web database and sample screen view of the web interface integrated with database.

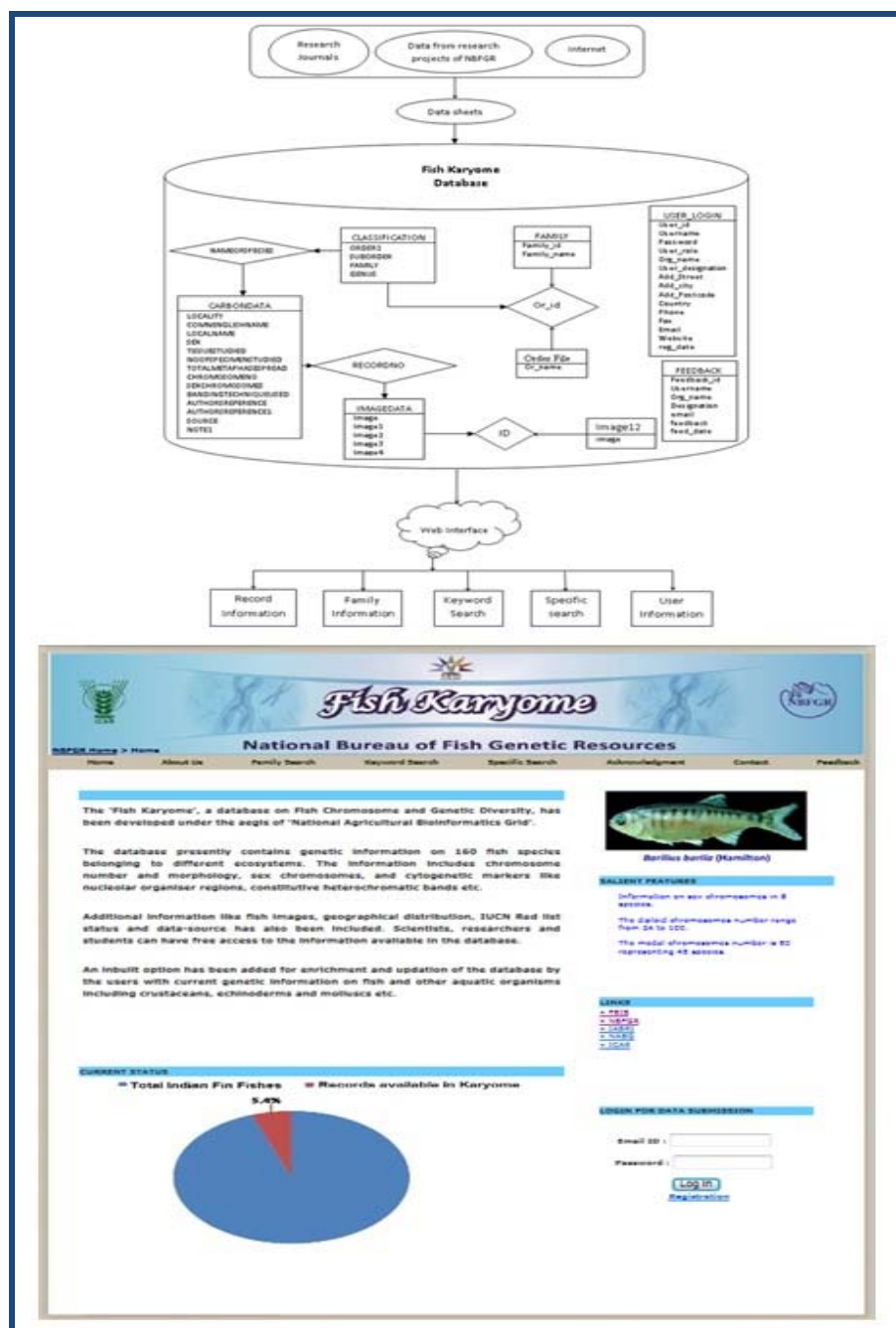

Figure 1: Architecture and sample screen viwe of the web interface of Fish Karyome Database

\section{Results:}

\section{Accessing the Fish Karyome database content}

At present, our database provides karyological and phenotypic information about 171 fish species of India to the public on web page at URL: http://www.nbfgr.res.in/fishkaryome/ When the home page is accessed, a user web interface with six hyperlinks entitled "About us", "Family search", "Keyword search", "Specific search", "Acknowledgement", "Contact" and Feedback" is displayed. The user can get relevant information and work with the database through these hyperlinks. To access and update the database content, we integrated various search, browsing, and data submission tools through user login section only for authenticated users in our database through the web interface.

\section{Querying the database}

The web interface of the database provides a rich set of functions for searching the database. These search functions are 'Family Search', 'Specific Search' and 'Keyword Search'. These search function allows the user to make query with the database in the interactive way. 


\section{Family search}

This search allows the user to select a family from the list box displaying 43 families to view individual fish species available in the selected family. (Figure 3) shows the sample screen view of 'Family search' further selection of the fish species by the user provides the detailed karyotype and phenotypic information along with images.

\section{Specific search}

This search provides the three options namely 'Order', 'Species' and 'Locality' to the user to view the information by selecting the option of interest. Clicking the radio button against the each option eventually provides the scientific name, common name and references information on fish species along with link. The link provides the detailed karyotype and phenotypic information about 171 fish species belonging to 10 orders and 88 localities.

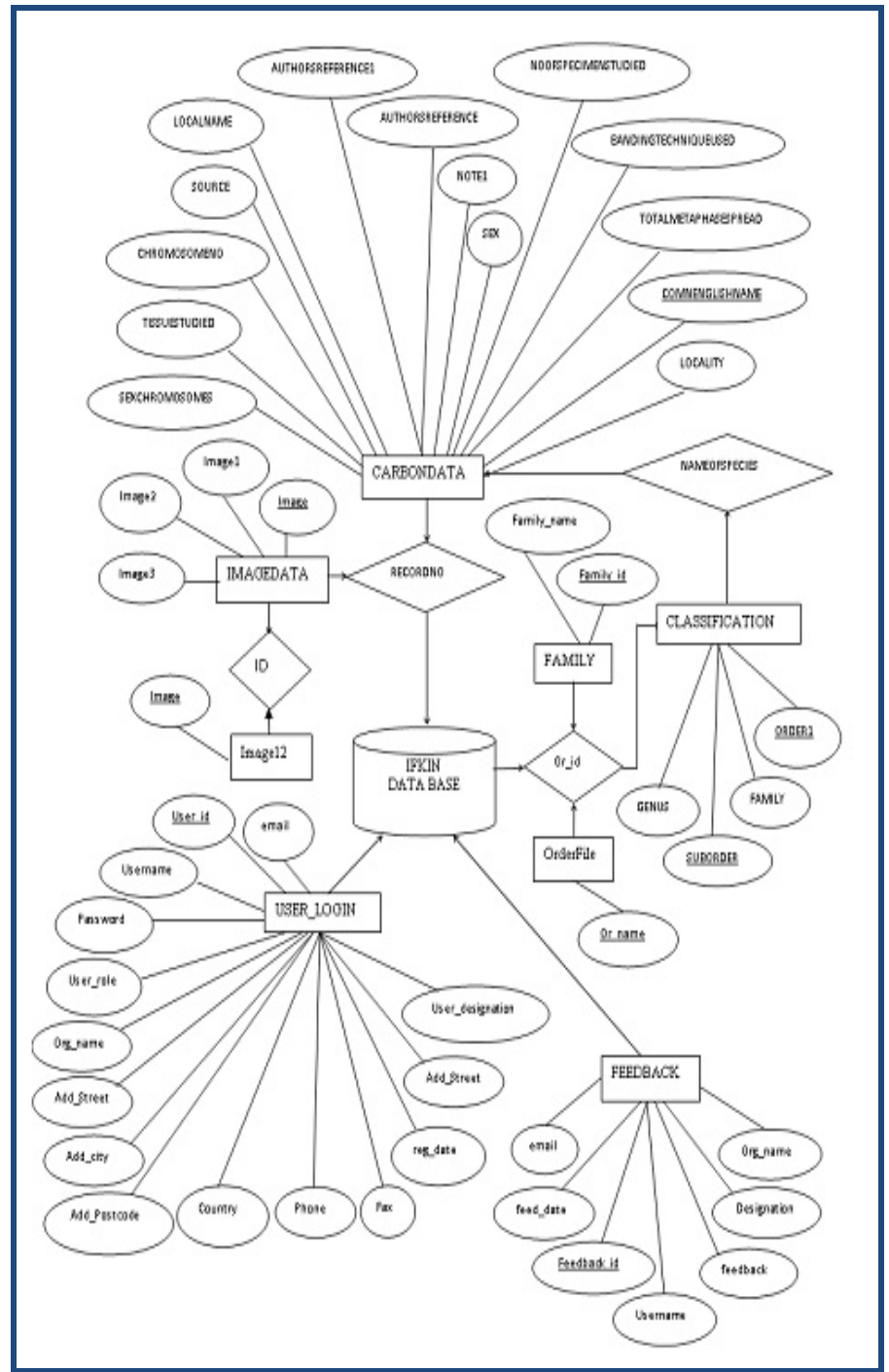

Figure 2: E R- Diagram representing structure of the database for Fish Karyome

\section{Keyword Search}

This is a simple text based search that allows the user to perform the search on all fields of the database based on the keyword using all, any one and exactly tools, either of the search criteria. This provides freedom to the user to query with the database and view the information based on the keyword of interest.

\section{Data Management}

To work with data, we integrated the database management functions in the web interface for security reasons. These functions are only available to the authenticated users and here the user can not only submit and upload the data but also modify the submitted data through query with the database.

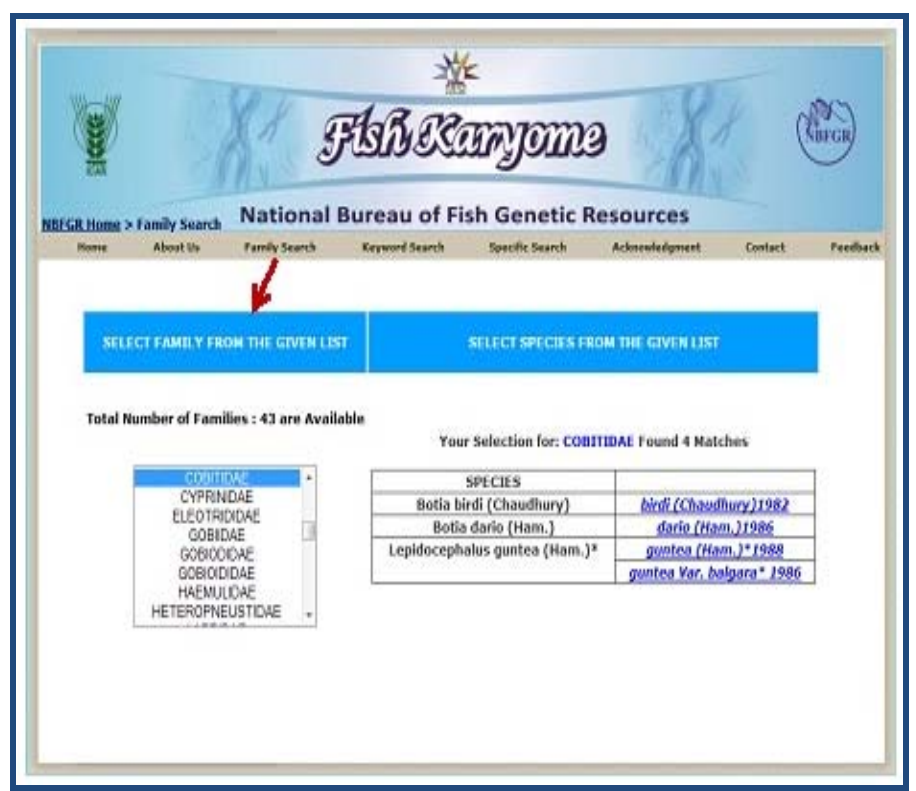

Figure 3: Family search for displaying the information

\section{Discussion:}

Genetic characterization of fish particularly economically important and threatened species is pre-requisite for genetic improvement programs and planning for their sustainable conservation. Some of the classical cytogenetic markers have been utilized earlier for characterization of fish species as well as to establish phylogenetic relationship and resolving taxonomic ambiguity [4, 16]. Additionally, cytogenetic markers have been found useful for genetic discrimination of mahseer species i.e. T. khudree, T. mussullah, T. putitora, T. tor, T. chelynoides, T. progeneius and Neolissochilus hexagonolepis based on the karyomorphology, number and position of nucleolar organizer regions (NORs) [4]. In the past efforts were made to develop the databases for vertebrates [17], on chromosome research [18] and chromosome images [19]. [19] Constructed a database system named CHRONIS (Chromosome and NanoInformation System) to collect images of animal chromosomes and related nano-technological information. Keeping in view the growing importance of fish karyological information in documentation and management of fish genetic resources [20, 21] the Fish Karyome is a new database from where the karyological information could be shared with the scientific community. The review of literature on database related to fish cytogenetics indicated that no such database is available in India and globally that provides the comprehensive karyotype information in addition to phenotypic information on fishes. Researchers can use our database to access images of chromosomal complements of a particular species and to make a comparative study of karyotypes of closely related fishes. The database has wide range of applications in species 
characterization and identification, chromosomal mapping, searching sex determination, karyo-evolution and systematics of fishes.

\section{Conclusions and future directions}

To the best of our knowledge this is the first endeavour to construct an integrated database of karyotype images and information on Indian fishes. Our database system contains classical karyotype images of fish chromosomes as well as phenotypic information and is a powerful research tool for researchers working on fish chromosomes. The database has been kept open through World Wide Web for everyone to view the records of karyological information. We have also provided a submission panel that allows the users to upload their data voluntarily from the panel. It is planned to make further modifications to improve the usability of the database by including the chromosome images of more fish species and by linking our database to other genomic resource databases. We also intend to rearrange all the karyotype images stored in our database according to the taxonomic trees. It is expected that Fish Karyome will become a more useful tool for researchers working in the field of fish cytogenetics and genomics.

\section{Acknowledgement:}

Authors are thankful to the National Agricultural Bioinformatics Grid (NABG), under National Agricultural Innovation Project (NAIP), ICAR, and New Delhi for providing financial support and the Director, NBFGR, Lucknow for providing necessary facilities to carry out this part of work.

\section{References:}

[1] Amemiya CT et al. Genetica. 1988 76: 81

[2] Manna GK et al. C I S Japan. 1974 16: 26

[3] Phillips RB et al. Cytogenetics and Cell Genet. 1988 48: 9

[4] Kushwaha B et al. Chromosome Science. 2001 5: 47

[5] Gold JR \& Amemiya CT, Genome. 1987 29: 481 [PMID: 3609741]

[6] Menon AGKJ. Bombay Nat Hist Soc. 1992 89: 210

[7] Das JK \& Khuda-Bukhsh AR, Genet Mol Res. 2007 6: 284 [PMID: 17573658]

[8] Froese R et al. World Wide Web electronic publication. 2009 version $(02 / 2009)$

[9] Kushwaha B et al. Indian Journal of Geo-Marine sciences. 2011 40: 62

[10] Lakra WS et al. Indian J Anim Sci. 1991 61: 342

[11] Manna GK, Fish Genetics in India. 1989 21: 46

[12] Nagpure NS et al. J Marine Biol Assoc India. 2006 48: 267

[13] NBFGR Special Publication. 1998 No.1:332

[14] Singh LB et al. Proc Nat Acad Sci India. 1997 67: 137

[15] National Bureau of Fish Genetic Resources 2007 copyright Reg.No. SW. 3342/2007

[16] Andreata AA et al. Genet Mol Biol. 2006 29: 1

[17] Rao VK et al. Mutat Res. 2005 583: 105 [PMID: 15927870]

[18] Jones RN et al. Cytogenetic and Genome Research. 2004 106: 149

[19] Toyabe S et al. Chromosome Res. 2005 13: 593 [PMID: 16170624]

[20] Pisano E et al. Science Publishers. 2007 510P

[21] Ryoichi Arai Springer Verlag, Tokyo Japan. 2011348 P

Edited by $P$ Kangueane

Citation: Nagpure et al. Bioinformation 8(9): 440-444 (2012) License statement: This is an open-access article, which permits unrestricted use, distribution, and reproduction in any medium, for non-commercial purposes, provided the original author and source are credited. 


\section{Supplementary material:}

Table 1: List of selected parameters to collect the karyotype and phenotypic Information about the fish species

\begin{tabular}{llll}
\hline TYPE OF INFORMATION & PARAMETRS & SUB PARAMETERS & DATA TYPE \\
\hline PHENOTYPIC & TAXONOMY & ORDER & TEXT \\
& & TEXT \\
& & SUBORDER & TEXT \\
TEXT \\
LOCAL NAME & FAMILY & TEXT \\
& SEX & COMMON NAME & TEXT \\
& NUMBER OF SPECIMENS & & TEXT \\
& TISSUE TYPE & NUMBER \\
GEOGRAPHICL DISTRIBUTION & & TEXT \\
& IUCN RED LIST STATUS & & TEXT \\
SPECIES PICTURE & & TEXT \\
& KARYOTYPE & IMAGE \\
& & STRING \\
& & KARYOTYPE FORMULA & NUMBER \\
& METAPHASES COMPLEMENT STUDIED & NUMBER \\
& DIPOLID CHROMOSOME NO & NUMBER \\
REFERNECES & FUNDAMENTAL ARM NUMBER & TEXT \\
& SEX CHROMOSOMES & TEXT \\
& CHROMOSOME BANDING & IMAGE \\
& AUTHOR & KARYOTYPE PICTURE & TEXT \\
& YEAR & & NUMBER \\
& SOURCE & & TEXT \\
\hline
\end{tabular}

Table 2: Fish Karyome Database Table name and their information

\begin{tabular}{lll}
\hline Table Name & Discription & No. of records \\
\hline Classification & contain all the record of different species, Family \& Order & 330 record \\
Carbondata & contain all the record of different species & 377 record \\
Family & contain family information of the species & 38 records \\
Feedback & contain the feedback information data of the user & 18 records \\
OrderFile & contain order of the species & 11 records \\
ImageData & contain karyotype and physical images of the species & 161 records \\
Image12 & contain image id and image name of the species & 289 records \\
User_Login & contain user registration information detail & 15 records \\
\hline
\end{tabular}

